\title{
A reverse logistics chain mathematical model for a sustainable production system of perishable goods based on demand optimization
}

\author{
Saeed Tavakkoli Moghaddam ${ }^{1} \cdot$ Mehrdad Javadi $^{2} \cdot$ Seyyed Mohammad Hadji Molana ${ }^{3}$
}

Received: 15 May 2018/Accepted: 12 August 2018/Published online: 18 August 2018

(C) The Author(s) 2018

\begin{abstract}
Sustainability in the supply chain means pushing the supply chain to focus on social, economic and environmental aspects, and addressing the existing problems in the traditional supply chain. Considering the importance of evaluating supply chain networks, especially in the field of perishable commodities, this paper aimed to design a mathematical model for the reverse supply chain of perishable goods, taking into account the sustainable production system. In this research, four objective functions were considered to maximize profitability and the level of satisfaction with the use of technology, minimize costs and measure environmental impacts. The results of the implementation of the proposed model for a manufacturing company show that objective functions are sensitive to demand, so the change in demand changes the objective functions, in particular the profitability function.
\end{abstract}

Keywords Reverse logistics chain network $\cdot$ Sustainable production system $\cdot$ Perishable products $\cdot$ Mathematical modeling

\section{Introduction}

Reduction in raw materials, increase in pollutants and the extent of pollution caused by them have been important issues for organizations in recent decades. In addition, failure to observe ethical responsibilities will lead to increased costs and thus reduced profitability. Sustainable supply chain management is rooted in sustainability and includes an extensive approach to supply chain management. Sustainability in the supply chain means pushing the supply chain to focus on social, economic and environmental aspects, and addressing the existing problems in the

Mehrdad Javadi

mjavadi@azad.ac.ir

Saeed Tavakkoli Moghaddam

saeed.tavakkolimoghaddam@srbiau.ac.ir

Seyyed Mohammad Hadji Molana

molana@srbiau.ac.ir

1 Young Researchers and Elites Club, Science and Research Branch, Islamic Azad University, Tehran, Iran

2 Department of Mechanical Engineering, South Tehran Branch, Islamic Azad University, Tehran, Iran

3 Department of Industrial Engineering, Science and Research Branch, Islamic Azad University, Tehran, Iran traditional supply chain. Sustainable supply chain includes all logistics costs from an economic point of view, reducing the amount of contaminants released from an environmental point of view, and reviewing social responsibility from a social point of view.

The supply chain for perishable products includes products with a durable shelf life and limited production, the management of which requires making right decisions (Katsaliaki et al. 2014). Rapid food spoilage leads to a loss in the volume of many foods and more pressure on FSCs; it also reduces the quality, profitability and sustainability of food. Some of the food losses that occur after harvesting and in the supply chain transportation are inevitable. According to FAO reports, $20-60 \%$ of the total production in all countries and one-third of food products for human consumption in the world (about 1.3 billion tons per year) are lost after harvesting.

With an increase in food demand in the world, production is one of the ways to meet these needs; in addition, reducing waste in each stage of the food chain can be an option for productivity when increasing production. Many cases in manufacturing operations can be effective in causing waste, most of which, according to Lemma et al., are inefficiency in production, storage and transportation. In addition, inappropriate planning and supply chain 
management practices are the main operational reasons for wastes in different countries (Lemma et al. 2014).

At the strategic level, the key issue is the design or reengineering of the supply chain network, which addresses the location and evaluation of facilities and the flow of materials through the network. In the meantime, supply chain management is seeking to achieve goals such as effective economic competitions, time and quality of service, specifically in the economic environment characterized by the globalization of transactions and acceleration of industrial cycles (Eskandarpour et al. 2015). Coordination, integration and management of business processes in the supply chain will determine the competitive success of food companies. Sustainable food supply chain management includes procurement of raw materials, production and distribution, and processes for collecting used or unused products, to ensure social, economic and environmental sustainability (Bloemhof and Soysal 2017).

According to Bloemhof and Soysal, about $40 \%$ of food waste is related to supply chain activities, such as transportation that requires specific conditions and storage, management and packaging of perishable products. So, supply chain sustainability means improving the mix of various and sometimes contradictory factors, and how to combine economic, social and environmental indicators (Bloemhof and Soysal 2017).

Due to competition, changes in customer demand and legal issues, corporate executives need to focus on aspects of the sustainability of value creation, including a new set of challenges in decision making. Companies are trying to develop products with a certain quality and minimal cost. Today, the environmental and social performance of products beyond the entire life cycle of the product should be taken into account. From an environmental point of view, product design should lead to products that are characterized by reducing the severity of harmful substances, less input of toxic materials, decomposition, durability, ease of recovery, and less energy consumption and life span. Stindt argued that supply chain design is a mutual planning issue that involves all processes of the value chain of the core company with interfaces with the supplier and consumer that shows the resources and flow of materials (Stindt 2017). Recently, more companies have turned to using sustainable proactive strategies and management operations of an evolving sustainable supply chain. In the meantime, researchers considered closed loop supply chain (CLSC) as one of the most important factors for achieving sustainable operations. In the modern world of business, focus is not only on reducing costs and increasing profits, but also on achieving sustainability and creating a balance between social responsibility, environmental protection and economic prosperity; these factors result in sustainability (Sgarbossa and Russo 2017).
In the present paper, considering factors such as reverse chain trend, sustainability and environment, perishable goods logistics, the use of different vehicles with certain speeds, and determining the details of supplier and retailers, attention has been paid to the productivity increase throughout the chain from beginning to the end, reduction of environmental damages and intra-chain productivity by four different objective functions: (1) minimization of supply chain design cost; (2) measuring the overall environmental impact over the network; (3) maximization of the profitability of the chain according to the product's novelty; (4) maximization of the level of satisfaction of using technology. The research also created a potential for measuring the performance and predicting the process by creating the objective function of satisfaction of the use of technology.

\section{Literature review}

The supply chain of products and services, especially when it comes to highly perishable products needing high level of services, is usually difficult to handle. In this case, simulation can offer a reliable approach toward studying and evaluating the processes and outcomes of such supply chains, and presenting suitable alternatives that can achieve optimal performance. Spoilage is a common phenomenon. Products may lose their value or quality suddenly or gradually. Fruits, vegetables, flowers, medicines, blood, dairy products, meat and food are prominent examples. Spoilage is the main concern of the supply chain, because the quality or value of most products is reduced over the life span. Spoilage is a nonlinear function that affects many factors, such as transportation types (Sazvar et al. 2016). Integrating objectives includes dimensions of sustainability, economic, environmental and social development, which are derived from the needs of stakeholders and customers (Galal and Moneim 2016).

Katsaliaki et al. have provided a game-based approach to facilitate decision-making on perishable products (Katsaliaki et al. 2014).

Researchers have used different methods to optimize the food supply chain and support the decision-making process, with some aiming to model food management and productivity, focusing on minimizing food waste along the supply chain. Food supply chains (FSCs) can be considered as a component of variable supply chain due to continuous and significant changes in the quality of food products throughout the supply chain until the final consumption. Also, due to the product's perishable nature, high volatility in demand and price, and increasing consumer concerns for food safety, FSC is a more complex chain that is tied to environmental conditions, as compared to other supply 
chains. To reduce food waste, proper study and performance is needed to improve the entire supply chain. Many approaches have been taken by researchers and practitioners to reduce food wastage. However, some studies were made by two-echelon inventory system for perishable items in supply chain (AriaNezhad et al. 2013). At the governmental level, many countries have taken various approaches to reduce waste. For example, at the production stage, the government supports farmers to improve the availability of agricultural development services and to improve harvesting techniques. In addition, improvement of the availability for storage, process improvement and packaging techniques, consumer education campaigns, etc., are used in a variety of areas.

In most researches, LP methods have been used to improve the supply chain. In addition, some recent researches have used advanced optimization techniques, such as an evolutionary optimization approach. This suggests that advanced modeling methods are at maturity stage and require further studies on perishable food products.

Lemma have considered production, transportation and inventory as the main causes of waste generation, which have high impacts on this stage of the supply chain. Lots of wastes are generated throughout the supply chain; however, little attention is paid to minimizing food waste (Lemma et al. 2014).

When the market is disturbed, that is, expected demand or variance varies from one period to another according to a probability principle, there is typically less likelihood of sustaining long-term partnerships in a booming market or a market with low demand variations. Further information on future fluctuations may not help the supply chain to sustain long-term partnerships due to strategic considerations of the partners. With availability of the market signal, the overall supply chain profit will increase, but the profitability of the retailer may be even worse (Sun and Debo 2014).

Some of the challenges in sustainable supply chain management are more important to be analyzed. In the same vein, companies' survival not only needs to make the sustainability issues involved in the plan, but also has to consider their strategic impact. Therefore, appropriate goals or functional indicators must be defined to achieve an appropriate decision-making process. Uncertainty is a factor that can deteriorate each model in supporting the decision making and reduce the importance of scheduled goals for such models. One of the origins of such uncertainty is the forecast mistakes that affect small and medium enterprises, especially in the food supply chain ( $\mathrm{Li}$ et al. 2014).

To assess the sustainability of the Greek dairy chain and the performance of individuals, Bourlakis et al. did an analysis using key indicators related to the efficiency, flexibility, accountability and product quality. The importance of these indicators has been assessed based on the perceptions of the key members of this chain. They did a comparative analysis in terms of sustainable performance indicators on the members of the Greek dairy chain. This analysis depicts many of the major functions of the members of this chain. In particular, there are significant differences regarding the cost of raw materials, production, operations, storage costs, delivery and distribution, flexibility in delivery to an alternative point of sale, the time of product protection, and the quality of the product packaging (Bourlakis et al. 2014). In general, a good supply chain performance needs awareness of customer needs and information changes (Fedrigotti and Fischer 2015). On the other hand, selection of sustainable suppliers in supply chain has a great importance (Ghoushchi et al. 2018).

Supply chain network design (SCND) models and methods have been the subject of many recent studies. Eskandarpour et al. analyzed 87 articles in the design of sustainable supply chain network covering mathematical models that include economic factors, as well as social or environmental dimensions. Nagurney has designed sustainable supply chain design for sustainable cities. The supply chain provides the necessary infrastructure for the production and distribution of products and services in the network economy and serves as a channel for manufacturing, transporting and consuming a range of products from food, clothing, automotive and high-tech products, even to health care products. Cities, as mainstream population centers, serve as major demand points, distribution centers and large storage facilities, transport providers and even manufacturers. For sustainable supply chains, focusing on sustainable cities, we can use a precise mathematical modeling with computational framework (Nagurney 2015). In another place, Galal and Moneim addressed the development of sustainable supply chain in developing countries and used AHP and other indicators to arrive at the final solution. They believe that supply chain sustainability is achieved by taking into account the economic, environmental and social aspects of the decision-making process. In developing countries where supply chains are often labor-intensive and environmental laws are still at their infancy, both environmental and social aspects must be taken into account. To achieve sustainability objectives, there is need for cooperation between supply chain managers. To maintain its position and role in the supply chain, each member must comply with environmental and social objectives. Competition must also be achieved through the fulfillment of customer requirements and economic aspects. It should be considered that the failure of one stage or player in the supply chain affects the performance of the entire supply chain and its competitions. The supply chain is considered as a system of individuals whose performance 
identifies the overall stability of the supply chain (Galal and Moneim 2016). There has been growing concern about the environmental and social effects of commercial operations in the last decade. The sustainability of the supply chain has attracted the attention of the academy and industry at the same time, taking into account the economic, environmental and social values. The issues of timely delivery and disposal of spoilt products are very worrying, especially for perishable and seasonal products such as the fresh crops. Sazvar introduced a multi-objective multi-supplier supply chain with perishable products in which a multi-objective linear mathematical method is used. Some variables, such as final consumer demand, the proportion of delayed orders and the rate of corruption are uncertain. The model of this paper simultaneously considers the economic and environmental objectives of perishable supply chains, emphasizing the details of the social aspects of the specific applications of the flower-picking industry. Integration of environmental and social aspects with economic considerations, which comprise the three dimensions of organizational sustainability, has gained importance in management decisions in supply chain management. As compared to the old SCM, typically, the focus is on financial and economic business performance, sustainable SCM with explicit integration of environmental or social objectives for the expansion of economic dimensions (Sazvar et al. 2016; Zhang et al. 2016).

Because the wastes in the emerging markets are high from harvesting to consumption in the supply chain of perishable food, such as fruit and vegetables, Balaji and Arshinder also analyzed the causes of waste generation in the supply chain of unsustainable foods. This study was conducted to identify the causes of food waste and their interdependencies and to analyze the interactions among them. This paper presents a fuzzy MICMAC and total interpretive structural modeling (TISM) (Balaji and Arshinder 2016). Fresh fruits and vegetables (FFV) are among the most important components of the retail chain and serve as a strategic product in attracting customers. The demand for fresh fruits is growing year by year. There is also a higher potential for the future. Food products come from a farmer's land to the end customer through a long chain of intermediaries like farmers, cooperatives, wholesalers, retailers, commissioners, which can cause a lot of waste (Agarwal 2017).

In order to design a sustainable supply chain based on post-harvest losses and harvest timing equilibrium, a sustainable two-way optimization model was presented by An and Ouyang in which a food company maximizes its profit and minimizes the post-harvest waste by expanding process facilities and purchases, price determination, a group of non-cooperative early distributor farmers, harvesting time, transportation, storage and market decisions which have been considered as product uncertainty and market equilibrium (An and Ouyang 2016).

Given the evolution of the agricultural sector and the new challenges facing it, effective management of agricultural supply chains is an attractive topic for research. Therefore, uncertainty management in the supply chain for the agricultural crops is important in researches on the latest advances in operational research methods to manage the uncertainty that occurs in supply chain management issues (Borodin et al. 2016).

In another study, in order to achieve multi-objective optimization for the design of a sustainable supply chain network with respect to distribution channels, a new method for designing SCN with multiple distribution channels (MDCSCN) was presented. By providing direct products and services to customers by available facilities, as a substitution for the conventional products and services, this model benefits them. Sustainable objectives, such as reducing economic costs, increasing customer coverage, and mitigating environmental impacts, contribute to MDCSN design. A multi-objective artificial bee colony (MOABC) Algorithm for solving the MDCSCN model, which integrates the priority paradigm coding mechanism, Pareto optimization and the swarm intelligence of the bee colony, was provided. The concept of sustainable development would be taken into consideration when it can reduce economic costs for chain companies, increase the flexibility of customer orders and reduce environmental impacts (Zhang et al. 2016).

Because of competition, customer pressure and legal issues, corporate executives need to focus, during decision making, on aspects of sustainability of value creation, including a new set of challenges. Companies are striving to develop products of a specific quality with minimal cost. Today, the environmental and social performance of products beyond its entire life cycle should be taken into account. From an environmental point of view, product design should result in products that are characterized by reduced material severity, lower input of toxic materials, biodegradability, durability, ease of recovery and lower energy consumption during the life cycle. Supply chain design is a mutual planning issue that involves all value chain processes of the core company with interfaces for supplier-consumer that illustrate the resources and flow of materials (Stindt 2017).

To optimize the fresh food logistics, an optimization model was proposed with three types of decision-making in gardening, which deal with the purchase, transportation and storage of fresh produce (Soto-Silva et al. 2017). The management of unsophisticated food in retail stores is very difficult due to the short life span of products and their spoilage. Many elements, such as price, shelf space allocation and quality that can affect the rate of consumption, 
should be considered when designing step for the retail chain perishable food. Xiao and Yang designed a retail chain for perishable foods and provided a mathematical model for a single-item retail chain, and determined the pricing strategy, shelf space allocation, and quantity assignment to maximize the overall profitability of the retailer with the use of tracer technologies (Xiao and Yang 2016).

In the contemporary business world, focus is not only on reducing costs and increasing profits, but also on achieving sustainability and balance between social responsibility, environmental protection and economic prosperity. These factors lead to sustainability; therefore, a preventive model in the food supply chain can be useful (Sgarbossa and Russo 2017).

In recent years, food safety incidents have occurred in many countries, and issues related to the quality of food and safety have become more socially appealing. Due to the concern about the quality sustainability of the food supply chain, many companies have developed a real-time data mining system to ensure the quality of the products in the supply chain. For food safety and quality issues, the food chain precautionary system helps in the analysis of the food safety risk and minimization of the production and distribution of poor quality or non-safe products. Precaution also helps in improving the quality of food due to ensuring the sustainability of the supply chain quality. Therefore, Wang and Yue introduced a data mining food safety precautionary system for a sustainable supply chain (Wang and Yue 2017). Other aspects of deteriorating items have been studied by several researchers (Singh et al. 2017; Sundara Rajan and Uthayakumar 2017; Uthayakumar and Tharani 2017).

\section{Problem statement and mathematical formulation}

Considering the problem statement, the assumption considered in the design process of the mathematical model as well as the proposed model solution is as follows:

- The number of retailers is known.

- The demand for retailer $l$ for the period $p$ specified with $d_{l p}$ is a specific variable, and retailers' demands are independent of each other.

- There are different vehicles with different capacities that should be considered.

- Every retailer/open top distribution center is visited at a maximum of once per period.

- Soft time windows are included.

- There is more than one vehicle for each route.
- If a retailer or open top distribution center needs service, there should be more than one vehicle for servicing.

- The time period is considered as 1 day.

- The capacity of manufacturers and distribution centers is limited.

- At all stages, vehicles are available from the morning and the maximum availability time for each vehicle is less than or equivalent to working time per day.

- Distribution centers meet retailers' demand, and manufacturers can meet the orders of distribution centers.

- Retailers and distribution centers can order more than they need (they also have the permission for storage).

- One type of product is considered.

- In retail and distribution centers, no return can be made.

- The time and cost of dispatching the vehicle are known.

- Travel cost and unit distance are specified.

- The cost of maintenance is known.

- The service time is specified for each retailer.

- The speed of the vehicle is known.

- Products should be ordered in such a way that none expires in the warehouse.

- The first round of work should start and end at the same open top production unit.

- The second round should start and end at the same center of the open top distribution center.

- Manufacturers cannot directly sell products to retailers.

Before dealing with the mathematical model, the sets, parameters and decision variables are described prior to the mathematical model.

\section{Sets}

$K$ : A set of various types of vehicles.

$M_{1}$ : Set of type 1 vehicles.

$M_{k}$ : Set of type $K$ vehicles.

Tech: Set of manufacturing technologies.

$M$ : Set of potential producers.

$D$ : Set of potential distribution centers.

$L$ : Set of retailers.

$P$ : Set of time intervals.

$N_{1}$ : Set of nodes including $\{M \cup D\}$

$N_{2}$ : Set of nodes including $\{D \cup L\}$

\section{Parameters}

$c_{i j}$ : The average cost of traveling from nodes $i$ to $j$. $\mathrm{OC}_{d}$ : The cost of opening the distribution center $d$. $\mathrm{OC}_{m}$ : The cost of opening the manufacturing unit $m$. $S_{c m e}$ : The cost of technology deployment that must be built in the production center $m$. 
$d_{l p}$ : Customer demand for retailer $l$ over time interval $p$. $\mathrm{VC}_{d p}$ : Variable cost for maintaining a product at the distribution center $l$ in the time interval $p$.

$\mathrm{VC}_{\text {mep }}$ : The cost of producing each unit at the production center $d$ with technology at the time interval $p$.

$\mathrm{FVF}_{k}$ : The fixed cost of every vehicle launched in the first round for a $K$-type vehicle.

$\mathrm{FVS}_{k}$ : The fixed cost of every vehicle launched in the second round for a $K$-type vehicle.

$\mathrm{EO}_{m e}$ : Environmental effects of the outdoor production unit $m$ with the technology $e$.

$\mathrm{EO}_{d}$ : Environmental impacts of open top distribution center $d$.

$\mathrm{VE}_{d p}$ : Environmental impacts of preserving each unit in the open top distribution center $d$ in the time interval $p$. $\mathrm{VE}_{\text {mep }}$ : Environmental impacts of manufacturing in each unit in the production unit $m$ with the technology level $e$ in the time interval $p$.

$\mathrm{ET}_{i j}$ : Average transfer of environmental effects from node $i$ to node $j$.

$D_{\text {Max }}$ : Maximum desirable number of distribution centers.

$M_{\text {Max }}$ : Maximum desirable number of producers.

$Q_{k}$ : Capacity of vehicle type $k$.

$q_{i p}^{m_{k} k}$ : Delivery time specified for vehicle type $k$.

$\mathrm{Cap}_{d}$ : Storage capacity of distribution center $d$.

$\mathrm{Cap}_{m e}$ : Producer Capacity $m$ for production with technology $e$.

$I_{d p}$ : The amount of product stored at the distribution center $d$ as inventory at time interval $p$.

$I_{l p}$ : The amount of product stored in retail $l$ as inventory at time interval $p$.

$\zeta$ : A confidence coefficient that allows distribution centers to store a percentage of their previous period delivered to retailers.

$\tau_{\max }$ : Maximum continuous period to keep a perishable foodstuff.

$D_{m, k p}$ : Distance of movement of vehicle $M_{k}$ type $K$ in time interval $p$.

WT: Working time per day.

$t$ : Time index.

$\mathrm{RT}_{i p}^{m_{k} k}$ : A re-run time for a vehicle $M_{k}$ type $K$ for node $i$ in the time interval $p$.

$\operatorname{dis}_{i j}$ : The distance between the nodes $i$ and $j$.

$S_{m, k}$ : Average speed of type $K$ vehicle $M_{k}$.

$\mathrm{ST}_{i p}^{m_{k} k}$ : The delivery distance assigned by a $k$ type vehicle $M_{k}$ for a node $i$ in the time interval $p$.

$u d_{i p}$ : Time to enter distribution center $i$ in time interval $p$.

$e d_{i p}$ : The earliest entry time for the time window for the distribution center $i$ at the time interval $p$. $l d_{i p}$ : The most delayed entry time for the time window for the distribution center $i$ at the time interval $p$.

$p d_{e p}$ : Cost of waiting penalty or waiting time unit for Distribution Centers $i$ at time interval $p$.

$p d_{l p}$ : Latency penalty fee or the delayed arrival time for distribution centers $i$ at the time interval $p$.

$p d_{i p}\left(u d_{i p}\right)$ : Time window deviation for distribution center $i$ in time interval $p$.

$\mathrm{HC}_{d p}$ : The earliest entry time for the time window for retail $i$ in the period $p$.

$\mathrm{HC}_{l p}$ : The most delayed entry time for the time window for retail $i$ in the period $p$.

$p b_{e}$ : The cost of a waiting time penalty or time unit for retailer $i$ at the time interval $p$.

$\alpha_{e}$ : The latency penalty fee or the delayed arrival time for retailer $i$ during the period $p$.

$q$ : Level of freshness.

$A_{i p}^{q}$ : The level of freshness of the products in the retailer $i$ at the time interval $p$.

$B_{i p}$ : The quality of retail product $i$ during the period $p$. $p d_{d p}$ : The latency penalty fee or the delayed arrival time for the manufacturing unit $i$ during the period $p$.

$u d_{d p}$ : Time to enter the manufacturing unit $d$ in time interval $p$.

$p r_{l p}$ : The latency penalty fee or the delayed arrival time for the distribution center $i$ during the period $p$.

$u r_{l p}$ : Time to enter the distribution center $l$ in the time interval $p$.

$u r_{j p}$ : Time to enter the retail $l$ in the time interval $p$.

$p d_{e d}$ : The latency penalty fee or the delayed arrival time for the manufacturing unit $i$ with the technology $e$.

$p r_{i p}$ : The latency penalty fee or the delayed arrival time for retailers $i$ during the period $p$.

$p r_{e p}$ : The latency penalty fee with the technology $e$ in the time interval $p$.

$l^{\prime}$ : Undefined retailers.

$N^{\prime}$ : Prohibition of circulation subsets.

$g_{j p}^{m_{k} k}$ : The working time for a $K$ type vehicle $M_{k}$ for the node $j$ in the time interval $p$.

\section{Decision variables}

$r_{d l p}^{m_{k} k}:$ If the vehicle $M_{k}$ type $K$, within the time interval $p$, travels the distance between manufacturers and distributors, otherwise 0 .

$r_{i j p}^{m_{k} k}$ : If the vehicle $M_{k}$ type $K$, within the time interval $p$, travels the distance $\operatorname{arc}(i, j), N_{2}$, otherwise 0 . 
$r_{l i p}^{m_{k} k}:$ If the vehicle $M_{k}$ type $K$, within the time interval $p$, travels the distance $\operatorname{arc}(i, j)$ from the retailer $1, N_{2}$, otherwise 0 .

$g_{l p}^{m_{k} k}$ : If the vehicle $M_{k}$ type $K$, within the time interval $p$, meets the retailer 1 . Otherwise 0 .

$\beta_{d l p}$ : If the distribution center $d$ services the retailer $l$ within the time interval $p$. Otherwise 0 .

$y_{d}$ : If the distribution center $d$ is opened. Otherwise 0 .

$z_{m e}$ : If the manufacturing unit $m$ with technology $e$, is opened. Otherwise 0.

$x_{m d p}^{m_{k} k}$ : If the vehicle $M_{k}$ type $K$, within the time interval $p$, travels the distance between manufacturers and distributors in $\operatorname{arc}(I, j)$, otherwise 0 .

$x_{i j p}^{m_{k} k}$ : If the vehicle $M_{k}$ type $\mathrm{K}$, within the time interval $p$, travels the distance $\operatorname{arc}(I, j) N_{2}$, otherwise 0 .

$q_{d p}^{m_{k} k}$ : If the vehicle $M_{k}$ type $K$, within the time interval $p$, meets the distribution center $d$, otherwise 0 .

$\eta_{l p}^{m_{k} k}$ : The amount of products delivered to the retailer 1 with the vehicle $M_{k}$ type $K$ within the time interval $p$. $\delta_{d p}^{m_{k} k}$ : The amount of products delivered to the distribution center $d$ with the vehicle $M_{k}$ type $K$ within the time interval $p$.

$h_{\text {mep }}$ : The amount of product produced in the manufacturing unit $m$ with technology $t$ within the time interval $p$.

\section{Mathematical modeling}

In this section, the four objectives of the research problem were first discussed; then, the constraints were introduced suitable to the problem.

$$
\begin{aligned}
\operatorname{Min} F_{1}= & \sum_{m \in M} \mathrm{OC}_{m} \sum_{m \in M} z_{m e}+\sum_{m \in M} \sum_{e \in T e c h} \mathrm{SC}_{m e} z_{m e}+\sum_{d \in D} \mathrm{OC}_{d} y_{d} \\
& +\sum_{p \in P}\left(\sum_{k \in K} \sum_{m_{k} \in M_{K}} \sum_{i, j \in N_{1}} c_{i j} x_{i j p}^{m_{k} k}+\sum_{k \in K} \sum_{m_{k} \in M_{k}} \sum_{i, j \in N_{2}} c_{i j} r_{i j p}^{m_{K} K}\right. \\
& +\sum_{m \in M e} \sum_{\text {Tech }} \mathrm{VC}_{m e p} h_{m e p}+\sum_{d \in D} \operatorname{VC}_{d p}\left(\sum_{l \in L} \beta_{d l p}\left(\sum_{k \in K} \sum_{m_{k} \in M_{K}} \eta_{l p}^{m_{k} k}\right)\right) \\
& +\sum_{m \in M} \sum_{d \in D} \sum_{k \in K} \sum_{m_{k} \in M_{K}} \mathrm{FVF}_{k} x_{m d p}^{m_{k} k}+\sum_{d \in D} \sum_{l \in L} \sum_{k \in K} \sum_{m_{k} \in M_{K}} \mathrm{FVS}_{k} r_{d l p}^{m_{k} k} \\
& \left.+\sum_{d \in D} \operatorname{Pd}_{d p}\left(u d_{d p}\right)+\sum_{l \in L} \operatorname{Pr}_{l p}\left(u r_{l p}\right)+\sum_{d \in D} \mathrm{HC}_{d p} I_{d p}+\sum_{l \in L} \mathrm{HC}_{l p} I_{L P}\right)
\end{aligned}
$$

The 1 objective function reduces the overall variable and fixed costs of supply chain design. The first part is the fixed cost of opening a production unit, and the second is the fixed cost of association with the consolidation and learning of technology. The third part is about the fixed cost of opening distribution centers. It is important to know that the above corrections are related to the first stage of a two-stage model that includes decisions that need to be made before identifying the demands and vehicle routes in different periods or the fixed costs of the opening. The remaining parts are related to the second stage. They show variable costs, and these decisions are made after demands have been periodically determined. Parts four and five are transportation costs for the first and second periods. The sixth and seventh sections represent variable costs in manufacturing units and distribution centers. The next two parts are the fixed costs of each round of the first and second periods. The next two are the fine of distortion of the time window and the final two parts of the cost of inventory of distribution centers and retailers.

$$
\begin{aligned}
\operatorname{Min} F_{2}= & \sum_{m \in M} \sum_{e \in \mathrm{Tech}} \mathrm{EO}_{m e} z_{m e}+\sum_{d \in D} \mathrm{EO}_{d} y_{d} \\
& +\sum_{p \in P}\left(\sum_{k \in K} \sum_{m_{k} \in M_{k}} \sum_{i, j \in N_{1}} \mathrm{ET}_{i j} x_{i j p}^{m_{k} k}+\sum_{k \in K} \sum_{m_{k} \in M_{K}} \sum_{i, j \in N_{2}} \mathrm{ET}_{i j} r_{i j p}^{m_{K} K}\right. \\
& \left.+\sum_{d \in D} \operatorname{VE}_{d p}\left(\sum_{l \in L} \beta_{d l p}\left(\sum_{k \in K} \sum_{m_{k} \in M_{K}} \eta_{l p}^{m_{k} k}\right)\right)+\sum_{m \in M} \sum_{e \in \text { Tech }} \operatorname{VE}_{m e p} h_{m e p}\right)
\end{aligned}
$$

The 2 objective function measures the overall environmental impact over the network. The first two parts are the environmental impacts related to the opening services of manufacturing units and distribution centers. The next two in the second phase are the environmental impacts associated with the marine transportation of products from production units to distribution centers in the first round and from distribution centers to retailers in the second. Finally, the two final sums are variable environmental impacts that arise from executive activities in production and distribution centers. All variables are described in constraints (35) to (44).

$$
\begin{aligned}
\operatorname{Max} F_{3}= & \sum d_{l p} \cdot A_{i p}^{q} \\
& -\sum \sum \sum \sum\left[\left(B_{i p} \cdot \mathrm{VC}_{m e p}\right)+\left(\delta_{d p}^{m_{k}} \cdot S_{c m e}\right)\right] \\
\operatorname{Max} F_{4}= & \sum_{s} p b_{e}\left[\alpha\left(\sum_{m} \sum_{e} \mathrm{EO}_{m e}\right)\right. \\
& \left.+(1-\alpha)\left(\sum_{c} \sum_{m} \sum_{e} S_{c m e}\right)\right]
\end{aligned}
$$

The 3 objective function indicates the maximum profitability of the supply chain according to the freshness of the products. This function consists of two parts; the first part expresses the demand based on the products' freshness, and the second part expresses the cost of production (constant and variable) based on product quality. The 4 objective function also indicates the maximum level of satisfaction with the use of technology due to its use in the 
production process based on the amount of pollutants and the construction costs.

\section{Constraints}

$\sum_{i \in N_{2}} \sum_{k \in K} \sum_{m_{k} \in M_{K}} r_{i l p}^{m_{k} k} \leq 1 \quad \forall l \in L, p \in P$

$\sum_{i \in N_{2}} r_{i l p}^{m_{k} k}=\sum_{i \in N_{2}} r_{l i p}^{m_{k} k}=g_{l p}^{m_{k} k}$

$\forall m_{k} \in M_{K}, k \in K, l \in L, p \in P$

$\sum_{d \in D} \sum_{l \in L} r_{d l p}^{m_{k} k} \leq 1 \quad \forall m_{k} \in M_{K}, k \in K, p \in P$

$\sum_{l \in L} \sum_{i \in N_{2}} d_{l p} r_{d l p}^{m_{k} k} \leq Q_{k} \quad \forall m_{k} \in M_{K}, k \in K, p \in P$

$\sum_{i \in L^{\prime}} \sum_{j \in L^{\prime}} r_{d l p}^{m_{k} k} \leq\left|L^{\prime}\right|-1$

$\forall m_{k} \in M_{K}, k \in K, L^{\prime} \subseteq L,\left|L^{\prime}\right| \geq 2, p \in P$

$\sum_{d \in D} \beta_{d l p} \leq 1 \quad \forall l \in L, p \in P$

$\sum_{l \in L} d_{l p} \beta_{d l p} \leq \operatorname{Cap}_{d} y_{d} \quad \forall d \in D, p \in P$

$\sum_{l \in L} r_{d l p}^{m_{k} k}+\sum_{i \in N_{2}} r_{l i p}^{m_{k} k}-\beta_{d l p} \leq 1$

$\forall d \in D, l \in L, m_{k} \in M_{K}, k \in K, p \in P$

$\eta_{l p}^{m_{k} k} \leq Q_{k} \times \sum_{i \in N_{2}} r_{d l p}^{m_{k} k} \quad \forall l \in L, m_{k} \in M_{K}, k \in K, p \in P$

$I_{l p-1}+\sum_{k \in K} \sum_{m_{k} \in M_{K}} \eta_{d l p}^{m_{k} k}=d_{l p}+I_{l p} \quad \forall l \in L, p \in P$

$\sum_{l \in L} \sum_{k \in K} \sum_{m_{k} \in M_{K}} r_{d l p}^{m_{k} k}=\sum_{i \in N_{1}} \sum_{k \in K} \sum_{m_{k} \in M_{K}} x_{i d p}^{m_{k} k}=y_{d}$ $\forall d \in D, p \in P$

$\sum_{d \in D} \sum_{k \in K} \sum_{m_{k} \in M_{K}} x_{d l p}^{m_{k} k} \leq \sum_{e \in \text { Tech }} z_{m e} \quad \forall m \in M, p \in P$

$\sum_{d \in D} y_{d} \leq D_{\text {Max }}$

$\sum_{m \in M} \sum_{e \in \mathrm{Tech}} z_{m e} \leq M_{\mathrm{Max}}$

$\sum_{j \in N_{1}} x_{i j p}^{m_{k} k}=\sum_{j \in N_{1}} x_{j l p}^{m_{k} k}=q_{i p}^{m_{k} k}$

$\forall i \in N_{1}, m_{k} \in M_{K}, k \in K, p \in P$

$\sum_{i \in N_{1}} \sum_{j \in N_{1}} x_{i j p}^{m_{k} k} \leq\left|N^{\prime}\right|-1$

$\forall m_{k} \in M_{K}, k \in K,\left|N_{1}^{\prime}\right| \subseteq N_{1}^{\prime} \mid \geq 2, p \in P$ $\sum_{d \in D} \delta_{d p}^{m_{k} k} \leq Q_{k} \quad \forall m_{k} \in M_{K}, k \in K, p \in P$

$\sum_{d \in D} \delta_{d p}^{m_{k} k} \leq Q_{k} \times \sum_{d \in D} \sum_{i \in N_{1}} x_{i d p}^{m_{k} k} \quad \forall m_{k} \in M_{K}, k \in K, p \in P$

$\sum_{d \in D} \delta_{d p}^{m_{k} k} \leq \operatorname{Cap}_{d} y_{d} \quad \forall m_{k} \in M_{K}, k \in K, p \in P$

$\sum_{e \in \text { Tech }} h_{m e p}=\sum_{d \in D} \sum_{k \in K} \sum_{m_{k} \in M_{K}} x_{m d p}^{m_{k} k} \delta_{d p}^{m_{k} k} \quad \forall m \in M, p \in P$

$h_{m e p} \leq \operatorname{Cap}_{m e} z_{m e} \quad \forall m \in M, e \in$ Tech, $p \in P$

$I_{d p-1}+\sum_{k \in K} \sum_{m_{k} \in M_{K}} \delta_{d l p}^{m_{k} k}=\sum_{l \in L} \sum_{k \in K} \sum_{m_{k} \in M_{K}} \eta_{l p}^{m_{k} k} \beta_{d l p}+I_{d p} \forall d$ $\in D, p \in P$

$I_{d p} \leq \xi\left(\sum_{p-\tau_{\max }-1<\tau<p-1} \sum_{m_{k} \in M_{K}} \sum \eta_{l p}^{m_{k} k}\right) \quad \forall d \in D, p \in P$

$I_{l p} \leq \sum_{P<\tau<P+\tau_{\mathrm{MAX}}} d_{l \tau} \quad \forall l \in L, p \in P$

$D_{m_{k} k_{p}}=\sum_{i \in N_{1}} \operatorname{dis}_{i j} x_{i j p}^{m_{k} k}+\sum_{i^{\prime} \in N_{2}} \operatorname{dis}_{i^{\prime} j^{\prime}} r_{i j p}^{m_{k} k} \quad \forall j \in N_{1} \mid j^{\prime} \in N_{2}$, $m k \in M_{k}, k \in K, p \in P$

$\sum_{i \in N_{1}} q_{i p}^{m_{k} k} \mathrm{ST}_{i p}^{m_{k} k}+\sum_{j \in N_{2}} g_{j p}^{m_{k} k} \mathrm{ST}_{j p}^{m_{k} k}+D_{m_{k} k p} / S_{m_{k} k} \leq \mathrm{WT}$

$m_{k} \in M_{k}, k \in K$

$u d_{j p}=u d_{i p}+\mathrm{ST}_{i p}^{m_{k} k}+\operatorname{dis}_{i j} / S_{m_{k} k}$ $\times x_{i j p}^{m_{k} k} \quad \forall i, j \in N_{1}, m_{k} \in M_{k} k \in K, p \in P$

$u r_{j p}=u r_{i p}+\mathrm{ST}_{i p}^{m_{k} k}+\operatorname{dis}_{i j} / S_{m_{k} k}$.

$\times r_{i j p}^{m_{k} k} \quad \forall i, j \in N_{2}, m_{k} \in M_{k} k \in K, p \in P$

$p d_{i p}\left(u d_{i p}\right)=\left\{\begin{array}{ll}p d_{e d}\left(e d_{i p}-u d_{i p}\right) & \text { if } u d_{i p}<e d_{i p} \\ 0 & \text { if } e d_{i p} \leq u d_{i p} \leq l d_{i p} \\ p d_{l p}\left(u d_{i p}-l d_{i p}\right) & \text { if } l d_{i p}<u d_{i p}\end{array}\right\}$, $\forall i \in D, p \in P$

$p r_{i p}\left(u r_{i p}\right)=\left\{\begin{array}{ll}p r_{e p}\left(e r_{i p}-u r_{i p}\right) & \text { if } u r_{i p}<e r_{i p} \\ 0 & \text { if } e r_{i p} \leq u r_{i p} \leq l r_{i p} \\ p r_{l p}\left(u r_{i p}-l r_{i p}\right) & \text { if } l r_{i p}<u r_{i p}\end{array}\right\}$;

$\forall i \in L, p \in P$ 
$r_{d l p}^{m_{k} k} \in\{0,1\} \quad \forall m_{k} \in M_{K}, k \in K, d \in D, l \in L, p \in P$

$g_{l p}^{m_{k} k} \in\{0,1\} \quad \forall m_{k} \in M_{K}, k \in K, l \in L, p \in P$

$\beta_{d l p} \in\{0,1\} \quad \forall d \in D, l \in L, p \in P$

$y_{d} \in\{0,1\} \quad \forall d \in D$

$z_{m e} \in\{0,1\} \quad \forall m \in M, e \in$ Tech

$x_{m d p}^{m_{k} k} \in\{0,1\} \quad \forall m_{k} \in M_{K}, k \in K, m \in M, d \in D, p \in P$

$q_{d p}^{m_{k} k} \in\{0,1\} \quad \forall m_{k} \in M_{K}, k \in K, d \in D, p \in P$

$\eta_{l p}^{m_{k} k} \geq 0 \quad \forall m_{k} \in M_{K}, k \in K, l \in L, p \in P$

$\delta_{d p}^{m_{k} k} \geq 0 \quad \forall m_{k} \in M_{K}, k \in K, d \in D, p \in P$

$h_{\text {mep }} \geq 0 \quad \forall m \in M, e \in$ Tech, $p \in P$

Constraint (5) indicates that each customer has been visited only once. Constraint (6) shows the current visit to each retailer at any time interval and guarantees that the vehicle will return to the original distribution center. Constraint (7) shows that in the second level, each vehicle leaves a maximum of one distribution center. Constraint (8) indicates that the capacity of each vehicle should be taken into account. Constraint (9) is the constraint of the elimination of circulation sets and ensures that each customer has been visited at any time interval. Constraint (10) states that each customer has entered a distribution center. The inequality (11) requires that in case a distribution center is closed, no retailer enters it. Otherwise, the overall demand of retailers by an open top distribution center could exceed its capacity. Constraint (12) states that the distribution center $d$ serves the retailer if a vehicle $M_{k}$ type $k$ leaves $d$ and reaches $l$ and $l\left(\beta_{d l p}\right)$ can also be equal to 1 if no vehicles go from $d$ to $l$. Constraint (13) shows that if the vehicle $M_{k}$ type $k$ does not visit the retailer $l$, then the product amount transferred from the vehicle $M_{k}$ type $k$ to $l$ should be zero. Constraint (14) shows the total balance in each retailer $l$. Constraint (15) shows that if a circulation enters the distribution center, the circulation must enter the retail; then, the distribution center is operationally balanced. Constraint (16) indicates that each circulation that leaves the manufacturing unit $m$ should be defined. Constraints (17) and (18) limit the maximum distribution centers used and open top manufacturing units. Constraint (19) imposes ongoing observations in each distribution center at any time interval. Constraint (20) prohibits the circulation subsets.

Constraint (21) indicates the capacity of each vehicle. Constraint (22) shows that if the vehicle $M_{k}$ type $k$ does not enter the distribution center $d$, then the amount of product sent to the distribution center $d$ by that vehicle must be zero and that the capacity of the vehicles should be taken into account. Inequality (23) states that the amount of product sent to the distribution center should be in line with its capacity. Constraint (24) requires that the product produced in the manufacturing unit $m$ with technology e at the time interval $p$ equals the amount of product to be delivered from that node. Constraint (25) indicates the capacity of the manufacturing unit $m$, and if no manufacturing unit $m$ is used, then one cannot claim any product. Constraint (26) applies balance to each distribution center $d$. Constraint (27) ensures that the distribution center $d$ has no inventory level higher than the total aggregate of products delivered by $d$ in the previous continuous time period $\left(\tau_{\max }-1\right)$. Constraint (28) ensures that retailer $l$ has no inventory levels above the overall demand over the next continuous time period $\left(\tau_{\max }-1\right)$. Constraint (29) calculates the delivery distance of each vehicle $M_{k}$ type $k$ in each time interval. Constraint (30) shows that the delivery time for a vehicle $M_{k}$ type $k$ at any time interval $p$ should not exceed the working time of each day. Constraints (31) and (32) show that at each interval, the arrival time for the $i$ and $j$ nodes is the same, plus the servicing time for node I with the vehicle in the node $i$, and the time to come from nodes $i$ to $j$ in first and second circulations. Finally, constraints (33) and (33) show that, for any time interval $p$, a penalty fee is incurred for the deviation from the time window because no arrival time exists for a node in the specified time interval in the first and second circulation rounds.

\section{Case study}

In this case study, the manufacturing group B.A was investigated. In this study, distribution of all types of ready-made foods of meat products to distribution centers was considered. This product should be consumed within 6 months from the time of production. Therefore, for this purpose, the importance of the subject was first introduced and then the details of the problem were addressed (Fig. 1).

As suggested in the mathematical modeling section (Sect. 3), the proposed model is a reverse logistical chain network model of the sustainable production system of perishable goods, which is used in this section. In this study, due to the sensitivity of meat products, it is considered to be a difficult type. Before proceeding to solve the model, the sustainable manufacturing system in the company under study was briefly described.

The Setareh Yakhi Asia Company delivers all types of Persian and Western ready-made food products with the most advanced and up-to-date methods of preparation, processing and packaging under the brand B.A. B.A production group, using today's modern technology and 


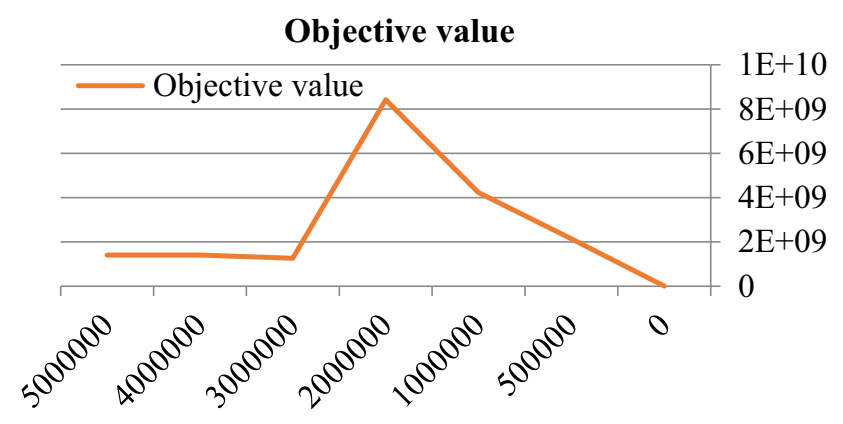

Fig. 1 The amount of objective function with variation in demand

specialists, as the first and largest producer of ready-made and semi-ready Iranian and international halal foods, and according to the current and future needs of the stakeholders, aims to satisfy its customers and meet their various needs by tireless endeavor through the implementation of participatory management, with the following policies:

- Compliance with national and international regulations and implementation of ISO9001-2008 quality management system requirements and ISO 22000-2005 Food Safety Management System.

- Client-oriented expansion at all levels of the organization and satisfying the consumers by implementing CRM system (Customer Relationship Management System).

- Continuous improvement of all processes in order to raise the level of quality and safety.

- Increasing the ability to "identify, assess, monitor and control" the risks to product safety and consumer health, and more efforts to maintain and improve GMP/ GHPs (desirable conditions for construction and sanitation).

- Increasing the employees' participation and empathy in decision making.

- Raising the level of knowledge of employees through practical and strategic training.

- Increasing productivity in key processes and achieving organizational excellence.

Creating and promoting effective inter- and intra-organizational communications: In this regard, all managers and staff are required to work toward achieving the abovementioned goals and try to increase the level of satisfaction of the stakeholders and control the risks to the consumers. Therefore, the management representative in the quality and food safety management system, with sufficient authority, is responsible for continuous monitoring, evaluation and ensuring the correct functioning of the above systems. For the first time in the country's food industry, designing products aimed at improving texture, taste, color, aroma and quality of food, as well as promotion of traditional and healthy Iranian foods that are unfortunately less common on the Iranian dining tables, such as vegetable omelet, potato omelet and cutlet, has been performed in the B.A. production group. For this purpose, in 1388, the formulation of more than 35 types of Iranian and foreign foods was performed under the supervision of reliable European and Iranian experienced experts in the food industry in cooperation with renowned Iranian chefs, and after the market test operations, they were gradually prepared for mass production and delivered to the consumer markets. B.A., ready-made foods production group, has been embracing the latest technology in the production of fully cooked, frozen foods with traditional Iranian cuisine by the highly advanced machines and the expertise of managers in a land with an area of over 20,000 sq.m and a subtraction of 9000 sq.m in the large industrial complex of Shiraz with various venues including the following sections:

A: The reception section for the red meat, consisting of below zero refrigerating room, as well as aging, bone removal, chopping, etc. (for warm meat).

B: The reception section for the white meat consists of above and below zero refrigerating room, the initial washing and cleaning, in order to prevent microbial contamination (considering that in chicken slaughterhouses, chickens are not cleaned completely). Then, automatic transference to the chopping system which can split up to 6000 chicken carcasses into 2-14 pieces per hour automatically.

C: Processing halls include two production halls: one for preparation of raw materials, the other for processing the product and packing it with the most advanced machinery and technology in the world. Therefore, the raw materials are received in compliance with all health conditions and after approval of the relevant systems, then stored in the best possible conditions and in the manufacturing halls, by using the standards of the USA and Japan, which are certainly the world's leading food producers. In order to prevent possible contamination, cold air generation and sterilizing equipment are used in the facilities to keep the temperature of the halls in all seasons at $12-15{ }^{\circ} \mathrm{C}$. Also, positive pressure systems combined with microbial filtration help the company comply with all conditions mentioned in HACCP and minimize the risk by the highest and most advanced technology and novel preparation, processing, packaging and marketing methods.

\section{Research data}

Since the company produces a diverse range of products like cooked foods, including chicken nugget, chicken and mushroom nugget, potato croquette, Krakow, ; semi- 
cooked foods, including hamburger, chicken burger, vegetable omelet, little omelets, ; and raw foods, including chicken kebab, Lari kebab, in various volumes, in this research, the supply chain of fried foods (chicken nuggets) was examined.

- Storage conditions: $18^{\circ}$ below zero

- Warehousing conditions: $18^{\circ}$ below zero, inside the carton and plastic pallet

- Package weight: $250 \mathrm{~g}$

- Bulk packaging weight: $2 \mathrm{~kg}$

- Number in the package: 9 pcs

The full list of additives and packaging materials together with the amount of consumption per ton of nuggets is shown in Table 1.

Company planning is usually announced to all of the manufacturing departments at the beginning of the year as a forecast for the whole year by the planning unit and with the cooperation of the trading department with regard to the capacity of the manufacturing equipment. During the year, the planning director, production manager and the commercial manager accurately determine the amount of the monthly production. In the meat industry, production of oil drop is allowed to be between 2 and $5 \%$, and it is $3 \%$ for this company. The company produces about 4500 to 5000 nuggets per month. The demand for nuggets is in an average of $200-250 \mathrm{t} / \mathrm{m}$, which is about $5.5 \%$ of the total factory production.

Changes in demand are an effective factor in maximizing target functions. Table 2 shows how much change in demand affects the target functions.

Table 1 Additive consumption and inventory of the first period

\begin{tabular}{lll}
\hline Type of material & Unit & Consumption/ton \\
\hline Active carbon & $\mathrm{kg}$ & 0.12 \\
Anti oxidants & $\mathrm{kg}$ & 0.08 \\
Acid citric & $\mathrm{kg}$ & 0.44 \\
Phosphoric acid & $\mathrm{kg}$ & 0.6 \\
Beta carotene & $\mathrm{kg}$ & 0.025 \\
Propylene glycol & $\mathrm{kg}$ & 0.63 \\
Liquid soda & $\mathrm{kg}$ & 5.5 \\
Catalyst nickel & $\mathrm{kg}$ & 1.6 \\
Aromatics & $\mathrm{kg}$ & 0.75 \\
Monodiglyceride & $\mathrm{kg}$ & 3 \\
Lecithin & $\mathrm{kg}$ & 1.5 \\
Potassium sorbate & $\mathrm{kg}$ & 1 \\
NaCl & $\mathrm{kg}$ & 3 \\
Cartons & - & 100 \\
Nylon & $\mathrm{kg}$ & 2.7 \\
Adhesives & - & 0.18 \\
\hline
\end{tabular}

Table 2 Sensitivity analysis of demand changes

\begin{tabular}{lc}
\hline$D$ (demand) & Objective function \\
\hline 0 & $-121,378$ \\
500,000 & $2,143,146,000$ \\
$1,000,000$ & $4,234,710,000$ \\
$2,000,000$ & $8,417,837,000$ \\
$3,000,000$ & $1,260,096,000$ \\
$4,000,000$ & $1,409,690,000$ \\
$5,000,000$ & $1,409,690,000$ \\
\hline
\end{tabular}

As shown in Table 2, demand changes lead to changes in the objective function, that is, with increase in the amount of demand, the company's profit also increases, and it is clear that when the demand does not exist, the amount of the objective function is negated. Therefore, the amount of optimized demand is created when the factory production is the same as the sales.

Table 3 describes the values of the four objective functions introduced in this study. As shown in the table, the two first objectives are minimized and the two following objectives are maximized; therefore, in sensitivity analysis for the first two functions that are minimized, the minimum and maximum values are displaced. Also, the model responses are ensured for (the feasibility of) all constraints, meaning that the optimal values obtained for all constraints are true.

\section{Conclusions}

Reducing costs and increasing the level of service (satisfaction) are the most important factors in today's market competition. In this regard, in the framework of a comprehensive systematic approach, supply chain management considers the coordination between the members in order to reduce costs and increase the level of service in providing a product or service to the customers. In this system, the total costs of the facility are a special priority. Efforts have been made to model and optimize the supply chain design. But there are a few research projects that target the design of supply chain networks comprehensively (taking into account both strategic and tactical issues simultaneously). Many of these attempts use definitive methods, while in the real world, definitive assumption is unreasonable. Therefore, it is necessary to consider uncertainty in investigations and decisions. On the other hand, taking into account the reduction of environmental impacts, considering the importance of the environment and pollution prevention is of great significance. Environmental damage 
Table 3 Results of the studied case calculations (together with sensitivity analysis)

\begin{tabular}{lrrr}
\hline Objective function & Minimum & Optimized value of the objective function & Maximum \\
\hline Objective 1 & $2,500,756,000$ & $3,750,009,781$ & $1,570,000,000$ \\
Objective 2 & $3,700,840,000$ & $3,205,685,000$ & $1,764,375,000$ \\
Objective 3 & $2,746,874,000$ & $3,746,870,000$ & $4,005,874,000$ \\
Objective 4 & $89 \%$ & $95 \%$ & $95 \%$ \\
\hline
\end{tabular}

is one of the most intangible costs that the entire community is its beneficiary.

In the sustainable supply chain, the effects of a chain on the environment are also addressed, and this, together with the inclusion of uncertainty and the study of the supply chain for perishable goods, forms an efficient collection that is addressed in this study. In this paper, introducing two objective functions to minimize the cost of supply chain design and environmental impacts and two functions to maximize profitability and satisfaction with the use of technology, all aspects of a supply chain for perishable goods are considered. The proposed model of this research has been implemented for the B.A. food production company. This unit uses up-to-date equipment for production. The results of the study indicate the effect of demand on the objective functions. By analyzing the sensitivity to demand, it was found that a change in demand would lead to a change in the level of profitability, and the optimal demand would be reached when the production amounts of the factory are the same as the sales. In this paper, proper objective functions for each of the four objectives were introduced with appropriate constraints that consider all aspects. Further research can be done to investigate other issues. For example, customer demand maximization functions can be added to target functions by using strategic planning and maximizing customer satisfaction. For example, customer demand maximization functions by strategic planning and maximizing customer satisfaction can be added to objective functions. Fuzzy numbers can also be used instead of crisp numbers.

Funding This research did not receive any specific grant from funding agencies in the public, commercial or not-for-profit sectors.

\section{Compliance with ethical standards}

Conflict of interest The authors declare no conflict of interest.

Open Access This article is distributed under the terms of the Creative Commons Attribution 4.0 International License (http://creative commons.org/licenses/by/4.0/), which permits unrestricted use, distribution, and reproduction in any medium, provided you give appropriate credit to the original author(s) and the source, provide a link to the Creative Commons license, and indicate if changes were made.

\section{References}

Agarwal S (2017) Issues in supply chain planning of fruits and vegetables in agri-food supply chain: A review of certain aspects. IMS Business School Presents Doctoral Colloquium, Kolkata

An K, Ouyang Y (2016) Robust grain supply chain design considering post-harvest loss and harvest timing equilibrium. Transp Res Part E Logist Transp Rev 88:110-128

AriaNezhad MG, Makuie A, Khayatmoghadam S (2013) Developing and solving two-echelon inventory system for perishable items in a supply chain: case study (Mashhad Behrouz Company). J Ind Eng Int 9:1-10

Balaji M, Arshinder K (2016) Modeling the causes of food wastage in Indian perishable food supply chain. Resour Conserv Recycl 114:153-167

Bloemhof JM, Soysal M (2017) Sustainable food supply chain design. In: Bouchery Y, Corbett CJ, Fransoo JC, Tan T (eds) Sustainable supply chains, Springer, pp 395-412

Borodin V, Bourtembourg J, Hnaien F, Labadie N (2016) Handling uncertainty in agricultural supply chain management: a state of the art. Eur J Oper Res 254(2):348-359

Bourlakis M, Maglaras G, Gallear D, Fotopoulos C (2014) Examining sustainability performance in the supply chain: the case of the Greek dairy sector. Ind Market Manag 43(1):56-66

Eskandarpour M, Dejax P, Miemczyk J, Péton O (2015) Sustainable supply chain network design: an optimization-oriented review. Omega 54:11-32

Fedrigotti VB, Fischer C (2015) Sustainable development options for the chestnut supply chain in South Tyrol, Italy. Agric Agric Sci Procedia 5:96-106

Galal NM, Moneim AFA (2016) Developing sustainable supply chains in developing countries. Procedia Cirp 48:419-424

Ghoushchi SJ, Milan MD, Rezaee MJ (2018) Evaluation and selection of sustainable suppliers in supply chain using new GP-DEA model with imprecise data. J Ind Eng Int 14:613-625

Katsaliaki K, Mustafee N, Kumar S (2014) A game-based approach towards facilitating decision making for perishable products: an example of blood supply chain. Expert Syst Appl 41(9):4043-4059

Lemma Y, Kitaw D, Gatew G (2014) Loss in perishable food supply chain: an optimization approach literature review. Int J Sci Eng Res 5(5):302-311

Li D, Wang X, Chan HK, Manzini R (2014) Sustainable food supply chain management. Int J Prod Econ 152:1-8

Nagurney A (2015) Design of sustainable supply chains for sustainable cities. Environ Plan B Plan Des 42(1):40-57

Sazvar Z, Sepehri M, Baboli A (2016) A multi-objective multisupplier sustainable supply chain with deteriorating products, case of cut flowers. IFAC PapersOnLine 49(12):1638-1643

Sgarbossa F, Russo I (2017) A proactive model in sustainable food supply chain: insight from a case study. Int J Prod Econ 183:596-606

Singh T, Mishra PJ, Pattanayak H (2017) An optimal policy for deteriorating items with time-proportional deterioration rate and 
constant and time-dependent linear demand rate. J Ind Eng Int 13:455-463

Soto-Silva WE, González-Araya MC, Oliva-Fernández MA, PlàAragonés LM (2017) Optimizing fresh food logistics for processing: application for a large Chilean apple supply chain. Comput Electron Agric 136:42-57

Stindt D (2017) A generic planning approach for sustainable supply chain management-How to integrate concepts and methods to address the issues of sustainability? J Clean Prod 153:146-163

Sun J, Debo L (2014) Sustaining long-term supply chain partnerships using price-only contracts. Eur J Oper Res 233(3):557-565

Sundara Rajan R, Uthayakumar R (2017) Optimal pricing and replenishment policies for instantaneous deteriorating items with backlogging and trade credit under inflation. J Ind Eng Int $13: 427-443$
Uthayakumar R, Tharani S (2017) An economic production model for deteriorating items and time dependent demand with rework and multiple production setups. J Ind Eng Int 13:499-512

Wang J, Yue H (2017) Food safety pre-warning system based on data mining for a sustainable food supply chain. Food Control 73:223-229

Xiao Y, Yang S (2016) The retail chain design for perishable food: the case of price strategy and shelf space allocation. Sustainability $9(1): 12$

Zhang S, Lee CKM, Wu K, Choy KL (2016) Multi-objective optimization for sustainable supply chain network design considering multiple distribution channels. Expert Syst Appl 65:87-99 